\title{
TV Commercials and Choice of Food among Children in Sabah, Malaysia
}

\author{
Andreas Totu ${ }^{1}$ Oswald A. Igau ${ }^{2}$ Murnizam Halik ${ }^{3}$ \\ ${ }^{1} C P K L L$, Universiti Malaysia Sabah,Malaysia \\ ${ }^{2}$ School of Business and Economics, Universiti Malaysia Sabah, Malaysia \\ ${ }^{3}$ School of Psychology and Social Works, Universiti Malaysia Sabah, Malaysia
}

\begin{abstract}
This study examines the relationships between television (TV) advertising and patterns of food choice among children. This relationship is crucial in understanding the intricate interplay among several interrelated variables such as TV viewing, preference for certain foods and the problem of obesity. Specifically, the study investigates the degree of recognition of adverts and patterns of food choice among lean, overweight and obese children. This study uses an experimental test, but the assessment of the effects of advertisements was undertaken through questionnaires. There were 50 participants involved in the experiment. The outcomes of the study indicate that TV advertisements make a substantial contribution to what food a child chooses. Although there were some variations in terms of responses between age groups and gender, generally, children seemed likely to choose fast foods after treatment. Further analyses were performed which revealed that media, particularly TV advertising, appear to contribute significantly in terms of influencing children to choose fast food, followed by taste. The study also seems to suggest that there is a strong correlation between the weight of a child and food choice. In short, children who were inclined to choose fast foods tended to be overweight or obese.
\end{abstract}

Keywords: TV advertising, food choice, obesity, children, Malaysia

\section{Introduction}

According to the World Health Organisation (WHO), there are more than 1 billion overweight adults globally and at least 300,000 are obese. The rate of obesity has tripled since the 1980s, particularly in North America, the United Kingdom, Eastern Europe, the Middle East and Africa, and Australasia. A sharp increase in overweight and obesity rates has also been observed in the Asia-Pacific region, which is a cause for concern among policy makers and communities alike, particularly in relation to youths and young adults. Children and young people are a major resource for progress and are the prime movers of innovation. Their imagination, idealism and collective energies form the creative impulse for the future of any nation (Rahman, 2001, p. 265). Rahman argues the importance of the role of children in the survival of any country in the world. Therefore, it is of paramount importance that children start off their lives properly.

The prevalence of obesity has become a phenomenon that is also known as "globesity". A significant body of literature on the subject of overweight has shown that such phenomena are the result of multiple influences, such as physiological and psychological, family and peer, economic and social, current lifestyles, and various internal and external factors. However, mass media, particularly television and advertisements, have often been criticised for their potential direct and indirect roles in promoting unhealthy food and food choices to viewers, which later contribute to the problem of obesity.

\section{What Do Children Prefer To Eat?}

Euromonitor International (2006) reported that the world's population is spending a large amount of money on fast food. Per capita consumption of fast food was led by the US at $\$ 566$ in 2005, followed by Canada, the UK and Australia with $\$ 456, \$ 390$ and $\$ 363$ respectively. This high level of per capita consumption demonstrates the importance of fast food as a lifestyle in these countries. Surprisingly, South Korea has a higher per capita consumption than several relatively wealthy European countries, namely Austria, Germany, Switzerland and Sweden, with \$239 spent on fast food in 2005.

The tendency to eat fast food is not only prevalent among the adult population, but more so among children. Children today have a high tendency to indulge in unhealthy foods and drinks, which are known to have high content of fats, sugar and salt (HFSS). A study conducted by the National Diet Nutrition Survey (NDNS) in 2008/2009 revealed that, generally, the British population was consuming more saturated fats, trans fats and added sugar than 10 years previously. Even though there was some reduction in the "unhealthy food" 
intake among British people, including children, generally the Big $5^{1}$, or rather the Big $6^{2}$, were still on the menu. Livingstone (2004) provided a review of various research outcomes in Britain and also found that snacking among British children is growing steadily, particularly in favour of foods with HFSS.

Snacking culture is also very widespread in the United States, especially among children, as reported in a study conducted by the University of North Carolina. The study, which was published in the Journal of Health Affairs in March 2010, reported a steady increase in snacking habits among children in the USA, these accounting for up to 27 per cent of children's daily calorie intake. Children, including young children, were found to snack very frequently, up to almost three times a day, and the most common types of food eaten during snack times were candy and salted crisps (Piernas\&Popkin, 2010).

According to the 2010 review by Euromonitor International, sweet and savoury snacks, which are high in sugar and salt, were still popular among Malaysian consumers. Kraft Foods Manufacturing (M) Sdn. Bhd. continued to take the lead in sweet and savoury snacks with its key brands Twisties, Chacho's and Cheezels and the newly launched TwistiesMegahot in 2009. Kraft Foods (M) Sdn. Bhd. held a value share of $13 \%$ of the snacks and confectionery market in Malaysia in the same year.

Apart from snacking, Malaysian consumers also show a tendency to eat Western-style fast foods. Euromonitor International (2010) reported a growing trend in foodservice in the country.

"More Malaysians are returning to foodservice outlets, such as fast food chains and fullservice restaurants, since the economy picked up in 2010. Hence, there is growing demand for foodservice products. In particular, Western-style foodservice outlets are gaining popularity in Malaysia, due to the increasing influence of Western culture, with consumers having become more aware of Western cuisine, coupled with rising disposable incomes." (Euromonitor International, Sept 2010)

Totu (2010) asserts that Quick Service Restaurants (QSR) such as Kentucky Fried Chicken (KFC), McDonald's and $\mathrm{A} \& \mathrm{~W}$ are becoming increasingly popular in Malaysia. This has led to a rise in other franchised Westernstyled restaurants such as Kenny Rogers Roasters, T.G.I. Friday's, Chili's Grill and Bar, and Roadhouse Grill. In addition, the number of family-type restaurants serving Italian and Mexican foods has also increased. Local franchised chains such as Marrybrown, Secret Recipe, Chicken Rice Shop and KLG restaurants, which offer similar menus to KFC and McDonald's, are also expanding.

The growth and expansion of fast food chains is indicative of food choice among Malaysians. A survey conducted by a local newspaper among teenagers aged between 16 and 21 years old in Malaysia established that pizza topped the list of favourite foods at $46 \%$ for the 253 interviewed, and hamburgers came in a close second. Local foods such as chicken and rice, Indian food, nasilemak, and noodles were all lower-rated choices (Shamsudin, 2002). The same eating trend should be observed for children because preferences regarding food usually develop when at a young age. Domestic demand for soft drinks is also increasing steadily owing to changes in consumer tastes and gradual increases in per capita income. The growth in non-alcoholic beverages was extraordinarily high in terms of expenditure, which implies an incredible consumption of soft drinks in Malaysia. Non-alcoholic drinks are extremely important in Malaysia, given that a large percentage of the population (Muslims) does not consume alcohol because of their religious law.

Suffice to say that children around the world continue to enjoy foods that contain high fats, sugar and salt. Such a calorie-dense diet raises concerns that children throughout the world are moving towards unhealthy eating pattern, which might lead to an increase in body weight and potentially death. They apparently have less of a preference for healthy or good foods such as fruits and vegetables. A study conducted by Moore and Tapper (2008) found that the average portion of fruit consumed by children in 24 hours is 2.54 but the average portion of sweets, chocolates and biscuits is 3.95 , and of crisps, 1.60. Children's fruit and vegetable intake is often lower than the nutritionally recommended intake and, when given the choice, children tend to select unhealthy food options (Warren, Parry, Lynch \& Murphy, 2008).

\section{Factors Contribute To Food Preferences}

The choice of what food and drink to consume is a key determinant in children's health. The choice is said to be influenced by various internal and external factors. The internal factors derive from an individual child, while external factors are the stimuli that encourage children to select certain types of food. Warren et al. (2008) suggest several important factors influencing selection such as parental food patterns, sensory perception, eating environments, socio-economic status, peer influence, knowledge about food and nutrition, school

\footnotetext{
${ }^{1}$ The Big 5 consists of confectionery, soft drinks, crisps/savoury snacks, fast foods and pre-sugared breakfast cereals.

${ }^{2}$ The Big 6 is the Big 5 plus pre-prepared convenience foods.
} 
practices, and the wider food environment such as prices, retail outlets, and obesogenic environments. Similarly, the European Food Information Council (EUFIC) (2005) revealed six basic determinants of food choice among people in European countries. These were biological, psychological and attitudinal, beliefs and knowledge about food, social, economic and physical.

However, the mass media has always been implicated as one of the significant contributors to children's food choice and the obesity epidemic. With the constant and wide exposure to television (TV) advertising, children are assumed to be influenced by its messages and images. Such perceived persuasive power of advertising has prompted advertising companies to increase their efforts and expenditure to persuade consumers to buy their products and services. This was reflected in the total advertising expenditures across the world amounting to $10.6 \%$ or $\$ 503$ billion in 2010 (Airlie, 2011). Media advertising expenditure alone for the top 100 global marketers showed a positive increase from $\$ 98$ billion in 2005 (Endicott, 2006) to slightly more than $\$ 107$ billion in 2009 (Johnson, 2010). According to Consumer International (2008), the food, drink and confectionery industries spent more than US\$16 billionon worldwide advertising in 2006. Such expenditure is astounding when compared to the amount of money spent by the World Health Organization (WHO) to improve the nutrition of the world's population.

The claimed pervasiveness of advertising on television has drawn significant interest among researchers. Several studies (Roberts \& Pettigrew, 2007; Karupaiah, Chinna, Loi, Lim \& Noor, 2008) showed that the number of advertisements for food with HFSS is still alarming in Australia and Malaysia. Considering the witty tactics of advertising, and children's inability to discern between truthful messages and untruthful ones, the issue has become more critical. Most advertising companies have developed their advertisements by associating the consumption of fast foods with the modern way of life - any other lifestyle can be viewed as outdated and un-cool. Such an association with a modern lifestyle could be seen as important to people, especially youths and children, because these categories of social groups are greatly involved with symbolic meanings.

According to a report prepared by the Australian Psychology Society (APS) (2009), entitled "Protecting Children from Junk Food Advertising (Broadcasting Amendment Bill) 2008", advertising media plays an active part in shaping children's perceptions of the world and their behaviour in several ways: by cultivating acceptance of the beliefs, values and attitudes that it portrays at a broad cultural level; by social learning, whereby children come to learn which attitudes and behaviours are accepted and rewarded; and by its impact on the formation, development and maintenance of cognitive scripts for how to behave in a variety of circumstances.

The same report also acknowledged that advertising has the potential for a range of effects on children, including increasing their product awareness, their positive attitudes towards a product (junk food), their inclination to buy or actual buying behaviour, their ideas about eating norms, and their tendency to request purchases from parents. In addition, it arouses cues for children, cravings, thought preoccupations, snacking behaviour, and increases the perceived value of certain products as rewards in families. One of their crucial research outcomes was that children exposed to foods that are high in salt, fat and sugar are more likely to develop a preference for these tastes and learn to associate having fun with eating junk food. The report was also cited as saying that young children are very vulnerable to being deceived and being exploited by manipulative advertising because young children are too young to discern the intent of advertising due to their lack of cognitive skills to defend themselves against persuasive messages.

\section{Children Vs. Advertising Influence}

The effectiveness of advertising is related closely to the understanding of the intent and purpose of advertising as well as the ability to distinguish between what is real (advertising) and unreal (programmes). Previous research (e.g. Bijmolt, Claassen\&Brus, 1998) has shown that some children are able to recognise the difference between advertisements and programmes. However, young children appear to have difficulty in distinguishing between advertising and reality and are unable to evaluate advertising claims. Such limitations mean that children are easily affected by advertising messages (Australian Psychological Society, 2009; Chaudhari\&Marathe, 2007; McDermott, Hastings, Stead, Carrigan\&Harris, 2008). The American Psychological Association (APA) reports that advertising targeting children below the ages of 7-8 years is inherently unfair because it capitalises on younger children's inability to attribute persuasive intent to advertising. As a result of this limitation, children below 7 years of age comprehend the information contained in television commercials uncritically, accepting most advertising claims and appeals as truthful, accurate, and unbiased (APA, 2004, p. 7).

Several factors might determine children's understanding of advertisements and ability to distinguish between commercials and programmes such as their age and gender. McDermott et al. (2008) argue that the principal variable is age because this would determine a child's cognitive development, including the ability to recognise, appreciate, be critical of and resist commercial messages. Early research from the 1970s and 1980s cited in Jennings and Wartella (2007) (e.g. Blosser\& Roberts, 1985; Butter, Popovich, Stackhouse \& Garner, 1981; Levin et al., 1982; Stephens \&Stutts, 1982) suggested that the majority of children could correctly 
distinguish an advertisement from programme content by the age of five. Nevertheless, although they were able to differentiate between advertisements and programmes, their understanding and level of distinction was very basic.

The outcomes of several early studies cited in Jennings and Wartella (2007) (Adler et al., 1977; Bever et al., 1975; Donohue et al., 1978; Meyer et al., 1978; Roberts, 1979; Sheikh et al., 1975; Ward et al., 1975) indicated that below the age of six the vast majority of children could not articulate the selling purpose of advertising. Children develop a better understanding of the intent and function of advertising after elementary school, i.e. aged between 9 and 12 years old. As they enter adolescence, they become aware of the tactics used in advertising (Boush, Friestad\& Rouse, 1994). Teenagers were found not only to be able to recognise the persuasive techniques used in advertising, but they were also able to detect whether advertisements were truthful or misleading (Mangleburg\& Bristol, 1998).

It can be generalised that advertising does have an impact on children; however, the strength of the influence is stronger in relation to younger children (7-8 year olds) compared to older children (9-12 year olds) and teenagers. The reason for this is that teenagers have already developed an advanced mental skill that enables them to interpret and make sense of advertising messages. However, the findings of Livingstone and Helsper (2006) in their study on "advertising literacy" reveal an interesting scenario pertaining to the effect of advertising on children and youths. They found a rather contradictory outcome whereby teenagers are more susceptible to advertising compared to younger children. They further assert that peer influence and financial autonomy were among the strongest factors that resulted in teenagers' greater consumerism compared to younger children.

Another aspect which has commonly been examined when analysing the effect of advertising is gender. Specifically, studies have looked at whether there is any difference in the effects of advertising between boys and girls. Reviews of the literature (e.g. Bijmolt, et al., 1998; Butter et al. 1981; Macklin 1987) show that none of the previous studies indicated any significant differences between boys and girls with respect to their ability to differentiate between advertisements and programmes or understand the real intentions of advertising.

Some studies have also looked at the relation between body weight and patterns of food choice. It was assumed that overweight and obese children would be more likely to choose HFSS foods compared to lean and normal weight children. However, the outcomes of previous research provide inconsistent results. Studies conducted by Goran et al. (1995), Stunkard, Berkowitz, Stallings and Shoeller (1999), and Treuth, Butte and Wong (2000) found no differences in the intake of high energy foods between overweight and non-overweight children. However, other research (e.g. Eck, Klesges, Hanson \&Slawson, 1992; Fisher \& Birch, 1995; Nguyen, Larson, Johnson \&Goran, 1996) suggests that the percentage of energy intake from fat might be higher in highrisk children.

A recent study of children and adolescents on calorie intake revealed a surprising finding that seems to reject earlier reports on this subject. The study examined a total of 12,316 children and adolescents aged from 1 to 17 years old using the National Health and Nutrition Survey data from 2001 to 2006 . The findings of the study revealed that generally overweight and obese children consume fewer calories compared to their healthy counterparts. Such a pattern of food intake occurred particularly among older children from 9 to 17 years old. Younger children ( 2 years old and younger) seemed to follow the common pattern, which is the greater the body weight the higher the tendency to consume high calorie and energy-dense foods. According to Dr Skinner:

"The flipped trend for energy intake between overweight/obese and healthy weight children and adolescents was the same for boys and girls, with boys tending to consume more calories than girls. The pattern continued into adolescence. Those 15 to 17 years of age who were overweight/obese consumed $2271 \mathrm{kcal}$ daily, whereas their healthy weight counterparts consumed $2537 \mathrm{kcal}$. Again, the pattern was similar for both sexes, including a higher energy intake for boys" (cited in Hoyle, 2010, p.1).

\section{TV Advertising And Food Preferences}

The relationship between television viewing, patterns and choice of foods and health has been investigated quite extensively by many researchers in the social sciences and medical and nutritional fields, particularly in the West. However, such research has not been sufficiently developed outside the Western world, including Malaysia. Several studies have tried to examine the relationships between TV (advertisements) viewing and children, but not exclusively related to food preference and/or obesity, such as the studies by Totu (2010), AnuarZaini, Lim, Low and Harun (2005) and Karupaiah et al. (2008). Totu (2010) examined the relationship between Malaysian TV advertisements and youth's lifestyles and identities, paying special attention to consumer attitudes, desires and habits. The outcomes of the study showed a significant relationship between TV viewing and food preferences in Malaysia, particularly among youths in the urban areas. The preference for fast foods was reflected in the significant relationship between TV viewing and the attitudes towards and desire 
to eat fast food. The results of the study also appear to suggest that social, cultural and geographical structures and the individual's intimacy with traditional values and beliefs determine the effects of media texts on the viewers. However, this study did not look at the impact of TV viewing on body weight.

The impact of TV advertisements on children's food preferences and health has been given due attention among researchers in the United Kingdom. Some variations in the results from different studies were observed. Dickinson's (2000) study, funded by the Food Standards Agency, examined comprehensively the influence of television on the food choices of young people in the UK. The study found out that TV merely helps to shape the family schedule and the routine of people's daily lives. The strongest determinants of food choice were parents and other family members although the children themselves were active in selecting what foods to choose. The outcomes of Dickinson's study seem to support the notion of an active audience, which suggests the dynamism of audience reception.

Dickinson's (2000) study may not represent the many other studies on the same issue such as that by Halford, Gillespie, Brown, Pontin and Dovey (2004). They investigated the impact of TV advertisements on children's eating behaviour and health. They were more interested to uncover whether there is a direct causal relationship between advertising viewing and patterns of food choice among children. They devised the study to examine whether children attend to and recognise food advertisements more than non-food advertisements. They looked at the responses of children within different categories of body weight towards food advertisements based on Schechter's externality theory. A total of 42 school children (18 males, 24 females) aged 9-11 years old from a Liverpool primary school participated in this study. Three groups were created, lean, overweight and obese, based on body mass index (BMI), as the basis for comparison in this study. The results showed that obese children recognised a greater number of food advertisements than non-food advertisements from TV. A similar effect was seen in the overweight children, whereas in the children with a BMI in the healthy range this difference between conditions did not appear. Moreover, an experimental study by Chernin (2008) in the United States, which was conducted to examine the effects of food marketing on children's preferences, found advertising made a contribution to children's food choice (cited in Davies, 2010).

A review conducted by the Institute of Medicine of the National Academies (IOM) (2005) similarly found positive relationships between food advertising and children's food knowledge, choice and behaviour. The IOM analysed the resultsof 123 published, peer-reviewed studies addressing links betweenfood marketing and children's food preferences, requests and consumption, and the conclusion of the review was that, among many other factors, food and beverage marketing influences the preferences and purchase requests of children, influences consumption at least in the short-term, is a likely contributor to less healthful diets, and may contribute to negative diet-related health outcomes and risks among children and youth.

The Obesity Policy Coalition (2008) conducted a thorough analysis based on a systematic and comprehensive literature review of empirical research on the effects of advertising on children, with recourse to three major studies (Hastings et al., 2006; Livingstone\&Helsper, 2006; McGinnis, Gootman\&Kraak, 2006). The review aimed to undertake a thorough examination of their findings on the impact of food promotion on children's knowledge, choices and behaviour with regard to food. The Obesity Policy Coalition (2008) summed up their review, supporting the positive impact of food promotion on children's food knowledge, preferences and behaviour. They suggested that,

"The clear and consistent conclusion of comprehensive and systematic reviews of the evidence is that food advertising influences the types of foods children prefer, ask for and eat... and that food advertising is harmful influence on children and is contributing to the childhood obesity problem...”(Obesity Policy Coalition Report, 2008, p. 10).

Nevertheless, Livingstone and Helsper (2006) argue for a proper rethinking about the roles of advertising in children's health conditions because the impact of advertising was not greatly significant. The finding of the insignificance of the relationship between TV advertising and food choice among children was also shared by Gunter and Furnham (1998). Thus, they concluded that TV advertising is not the only influencing factor nor is it the most important. However, their study did suggest that television advertising has some level of direct effect on the food preferences of children (aged 2-11 years old) by demonstrating that those exposed to particular messages are influenced in their food preferences when compared with those who did not see the messages. They also found a consistent association between overall television exposure and weight/obesity. This applies to both children and teenagers (cited in the Obesity Policy Coalition Report, 2008)

Based on these findings, there is sufficient evidence to suggest that food promotion, particularly advertising, makes quite a significant contribution towards children's knowledge, preferences and behaviour in relation to unhealthy foods. The inclination towards fast food and its claimed negative impact on body weight has become of paramount concern among all sections of society. Such concern prompted the initiation of this research. 


\section{Research Methodology}

This study used an experimental research design, specifically two-groups, random selection, and pretest, post-test method. Participants were selected from school children aged 7 to 12 years old from SekolahKebangsaanTobobon, Kota Kinabalu, Sabah. There were 50 participants for the experimental tests, divided into two groups: the treatment group (Group A) and the control group (Group B). Each group consisted of lean (healthy), overweight and obese pupils, based on body mass index (BMI) converted to a standard deviation score using the revised 1990 reference standards (Cole et al., 1990). Both groups were shown a mixture of SpongeBob Square Pants and Upin\&Ipin cartoon video clips. A stream of advertising which ran for about 5 minutes was inserted in between the cartoon clips. The length of advertising time, which was $25 \%$ of the total video clip, was equivalent to the length of advertising time in the actual TV programme (15 minutes in every one hour show).

\subsection{Materials}

TV advertisements and recognition tests. Video clips were used, which contained a cartoon, a collection of advertisement not related to foods and a collection of food-related adverts. Advertisements were recorded from four TV terrestrial channels, namely RTM1, RTM2, TV3 and NTV7. The participants' ability to recognise the adverts was assessed by identification of the product from a list of products that were either shown in the advertisements or not. Participants were asked to identify types of advertisements from a list of pictures of food and non-food related advertisements after the treatment.

Foods and choice of food. The children were presented with pictures of food and drinks: fast food available in quick food restaurants; foods such as ice cream, chocolate and candy; and local food and fruits. Participants were asked to tick the food and drink of their choice from the pictorial list. This was to determine the type of food they would choose after the treatment. If the inclination leant towards choosing fast food, it might suggest that the exposure to food-related advertisements contributed to the participant's food preferences.

\section{Results And Discussions}

The 50 participants were children aged from 7 to 12 years old. They were divided into two categories, namely middle childhood (7-10 years old) and early adolescence (11-12 years old). The majority of the participants $(72 \%)$ were in the middle childhood category and there were more females $(72 \%)$ than males (28\%). Out of the 50 participants, $30 \%$ were of Kadazandusuns origin, followed by Chinese (28\%) and Bajaus (24\%). Most participants were either obese or overweight, a combined percentage of 56\%, compared with $44 \%$ who were of normal body weight. Respondents seemed to spend more time watching TV during the weekends than on weekdays. Approximately $44 \%$ of the participants watched TV for more than 3 hours a day during the weekends, while around $72 \%$ watched TV for less than 3 hours on weekdays.

Several statistical tests were performed to assess the impact of TV advertisements on children's food preferences. Table 1 shows that the children who were exposed to food-related advertisements were more likely to choose fast foods than those who were not. The results of the experimental test seem to indicate that advertising plays a role in influencing children to choose fast food, in contrast to Livingstone\&Helsper (2006) research review outcomes.

Table 1

Contribution/correlation of exposure to TV advertisements to patterns of food choice among children

\begin{tabular}{|c|c|c|c|c|}
\hline Food choice after & Pre-treatment & Post-treatment & & \\
\hline Exposure to TV adverts & $r$ & $p$ & $r$ & $p$ \\
\hline Fast Foods & $0.309^{*}$ & 0.029 & $0.418 * *$ & 0.003 \\
\hline Good Foods & 0.314 & 0.923 & 0.282 & 0.121 \\
\hline
\end{tabular}

Further analyses of the strength of the influence of advertisements were performed and some interesting results were identified. One of the very important elements in assessing the effectiveness of advertising on its viewers, particularly children, is the extent of their cognition and recognition, as well as brand recall (Kirsh, 2010; Valkenburg\&Buijzen, 2005). 
Previous research (Ansari \&Dhital, 2006; Boush et al., 1994; Jennings \&Wartella, 2007; McDermott et al., 2008 ) has indicated in the respective studies that the reception, recognition and understanding of advertising messages and intent differed between age groups. In this study, early adolescent children appeared to have a better recognition and understanding of an advertisement's messages and intent compared to children in the category of middle childhood. The level of understanding may be attributed to their maturity, and hence their ability to be critical and resistant to advertising messages and intent (Ansari \&Dhital, 2006; Boush et al., 1994; Jennings \&Wartella, 2007; Schlaggar et al., 2002). The correlation test between recognition of advertisements and older children's food choice, as shown in Table 2, produced insignificant outcomes, which indicates that this group of children are more resistant to advertising messages; therefore, they appear less inclined to select fast food as compared to those in (younger) middle childhood.

Table 2

Inclination to choose fast food within the treatment group by age

\begin{tabular}{|c|c|c|c|c|c|}
\hline \multirow{2}{*}{\multicolumn{2}{|c|}{ Phase/age }} & \multicolumn{4}{|c|}{$\begin{array}{l}\text { Inclination to choose fast foods among } \\
\text { the treatment group }\end{array}$} \\
\hline & & Mean & $S D$ & $F$ & $P$ \\
\hline Pre-treatment & $\begin{array}{l}7-10 \text { years old } \\
11-12 \text { years old }\end{array}$ & $\begin{array}{l}13.80 \\
12.78\end{array}$ & $\begin{array}{l}2.40 \\
2.14\end{array}$ & 2.337 & 0.133 \\
\hline Post-treatment & $\begin{array}{l}7-10 \text { years old } \\
11-12 \text { years old }\end{array}$ & $\begin{array}{l}14.25 \\
13.07\end{array}$ & $\begin{array}{l}2.81 \\
2.45\end{array}$ & 0.228 & $0.026^{*}$ \\
\hline
\end{tabular}

Besides age differences, previous research has also been interested in examining the extent of the influence of advertisements on boys and girls. Gender studies have been always contested and challenging but interesting. Some theorists argue that there are differences between males and females in terms of attitudes, values and behaviour, but not as much in terms of brain structure and function as claimed by some other theorists. Consequently, this study investigated the difference between male and female participants with regard to recognition of advertisements and their inclination towards selecting fast foods.

Literature reviews conducted on the relationships between gender and the recognition and understanding of advertisement messages and intent have indicated that there is no significant difference between the two gender groups. In short, there is no difference in advertising effects between boys and girls. However, this study seems to suggest otherwise, whereby female participants seemed to have better recognition and understanding of advertisement messages and intent than did male participants.

Table 3

Inclination to select fast food within the treatment group by gender

\begin{tabular}{|c|c|c|c|c|c|}
\hline \multirow{2}{*}{\multicolumn{2}{|c|}{ Phase/gender }} & \multicolumn{4}{|c|}{$\begin{array}{l}\text { Inclination to select fast foods among } \\
\text { the treatment group }\end{array}$} \\
\hline & & Mean & $S D$ & $F$ & $P$ \\
\hline Pre-treatment & $\begin{array}{l}\text { Male } \\
\text { Female }\end{array}$ & $\begin{array}{l}13.91 \\
13.74 \\
\end{array}$ & $\begin{array}{l}2.40 \\
2.33\end{array}$ & 0.310 & 0.180 \\
\hline Post-treatment & $\begin{array}{l}\text { Male } \\
\text { Female }\end{array}$ & $\begin{array}{l}14.88 \\
13.91\end{array}$ & $\begin{array}{l}3.88 \\
2.39\end{array}$ & 0.254 & $0.017^{*}$ \\
\hline
\end{tabular}

${ }^{* *} P<0.01 / * P<0.05$

Such a level of understanding has a bearing on the extent of the influence of fast food-oriented advertisements on male and female children. The fact that females were more aware of the main purpose of advertisements may lead them to be more resistant to advertising messages and intent. Therefore, female participants were less likely to choose fast foods than were male participants. The likelihood of male children choosing fast foods became more apparent after the experiment, as shown in Table 3. The difference in preference for (fast) foods between boys and girls became more marked after treatment. This implies the contribution of advertisements in shaping children's attitudes and liking towards fast foods in Sabah.

One factor that contributes to the problem of obesity is the type of food consumed. A person who likes to consume unhealthy foods excessively might experience overweight or obesity problems. Some previous studies (Hastings et al., 2006; Hoyle, 2010; Institute of Medicine, 2005) have indicated robust and strong evidence that food promotion (through advertising) influences children's food preferences, food purchase requests, food consumption and the problem of obesity. Other research, such as that of Livingstone (2006), obtained a slightly different outcome. Livingstone (2006) found that although promotional efforts have a degree of influence on children's choice of foods, there is a lack of robust, significant evidence to support the importance of the role of advertising in the obesity epidemic. Livingstone (2006) only recognises a modest direct effect on children's food preferences, and also a modest but consistent association between overall television exposure and obesity. 
Table 4

Food choice among lean, overweight and obese children

\begin{tabular}{|c|c|c|c|c|c|}
\hline \multirow{3}{*}{\multicolumn{2}{|c|}{ Phase/type of body weight }} & \multicolumn{4}{|c|}{ Pattern of food choice } \\
\hline & & \multicolumn{2}{|c|}{ Fast foods } & \multicolumn{2}{|c|}{ Good foods } \\
\hline & & Mean & $S D$ & $F$ & $P$ \\
\hline Pre-treatment & $\begin{array}{l}\text { Lean } \\
\text { Overweight } \\
\text { Obese }\end{array}$ & $\begin{array}{l}1.97 \\
2.57 \\
2.94 \\
\end{array}$ & $\begin{array}{l}0.51 \\
0.61 \\
0.70 \\
\end{array}$ & $\begin{array}{l}1.45 \\
1.48 \\
1.00 \\
\end{array}$ & $\begin{array}{l}0.40 \\
0.41 \\
0.40 \\
\end{array}$ \\
\hline Post-treatment & $\begin{array}{l}\text { Lean } \\
\text { Overweight } \\
\text { Obese }\end{array}$ & $\begin{array}{l}2.00 \\
3.00 \\
3.20\end{array}$ & $\begin{array}{l}0.77 \\
0.90 \\
0.91\end{array}$ & $\begin{array}{l}1.51 \\
1.48 \\
1.05\end{array}$ & $\begin{array}{l}0.50 \\
0.41 \\
0.40\end{array}$ \\
\hline
\end{tabular}

This study however, identifies a strong association between exposure to food-related advertisements and the food choice of children. Generally, children in all weight categories were inclined to choose fast foods but further analyses of the data produced some interesting results. Table 4 indicates that overweight and obese children showed a strong inclination towards fast foods after they were exposed to stimuli, namely fast food advertisements. The significance of the difference became stronger after the experimental test was performed, particularly among the treated group of children. In contrast, although the lean children showed a slight increase in their inclination to select fast foods, the inclination to select good foods appeared to increase to a greater extent. This result appears to suggest that lean children tend to choose more good foods than fast foods.

\section{Conclusion}

The problem of obesity becomes a serious issue when it involves children, who are the future leaders of a country like Malaysia. Therefore, it is the responsibility of every citizen in Malaysia to address this potentially health-threatening problem. This study was undertaken to gain some light pertaining to this issue. This study also discovered that TV advertising plays an important role in promoting obesity through its interesting, amusing and entertaining presentations, which captivate the attention of children. Although there were different levels of influence between the age groups and gender, the overall outcome points to the fact that children are affected by the messages of advertisements directly or indirectly. The eventual consequences of the effects are the potential for the wrong choice of food type which finally results in an unhealthy body and a lack of wellbeing of a child. Therefore, positive and effective measures need to be initiated and implemented to address these problems. Only through the proper implementation of appropriate measures, from creating awareness to the imposition of relevant law, will Malaysia be able to bring about a conducive and favourable environment to ensure a better quality of life. Even though this study appears to suggest significant correlations between advertisements and food choice, such outcomes may not be taken as representative of the whole population because of some methodological limitations. This study used an experimental method but also employed a questionnaire survey to assess the impact of advertisements on children's food preferences. The number of respondents is probably somewhat small to generate commendable test results using a quantitative method. However, the outcomes of this study can provide a starting point for a larger and more comprehensive study in Malaysia on the same issue in the future.

\section{References}

[1] World Health Organization (2003). Obesity and overweight.Retrieved from www.who.int/dietphysicalactivity/media/en/gsfs_obesity.pdf

[2] Rahman, M. (2001). The globalisation of childhood and youth: New actors and networks in protecting street children and working children in the South. In H. Helve \& C. Wallace (Eds.) Youths, Citizenship and Empowerment. Aldershot, UK and Burlington Vt: Ashgate.

[3] Euromonitor (2006). Who eats the most fast food? Retrieved from http://blog.euromonitor.com/2006/08/who-eats-the-most-fast-food.html.

[4] Livingstone, S. (2004). Childhood obesity - advertising in context: Children's food choices, parents, understanding and influence, and the role of food promotion. Report submitted to OfCam UK. Retrieved from http://stakeholders.ofcom.org.uk/market-data-research/tvresearch/food_ads/

[5] Piernas, C., \&Popkin, B. M. (2010). Trends in snacking among U.S. children.Health Affair, March, 2010, DOI 10.1377/htlhaff.2009.0666.Retrieved

http://content.healthaffairs.org/search?fulltext=Snacking + Trends\&sortspec $=$ date\&submit $=$ Submit\&andorexactfulltext=phrase .

[6] Euromonitor (2010). Consumer foodservice by location in Malaysia. Retrieved fromhttp://www.euromonitor.com/consumer-foodservice-bylocation-in-malaysia/report

[7] Totu, A. (2010). Consumerism in Malaysia: Mass Media, Lifestyles and Identities. Kota Kinabalu: PenerbitUniversiti Malaysia Sabah.

[8] Shamsudin, M. (2002). Hail the pizza. The New Straits Times, 14

[9] Moore, L., \& Tapper, K. (2008). The impact of school fruit tuck shops and school food policies on children's fruit consumption: A cluster randomised trial of schools in deprived areas. Journal of Epidemiology and Community Health, 62, 926-931.

[10] Warren, E., Parry, O., Lynch, O. R., \& Murphy, S. (2008). "If I don't like it then I can choose what I want": Welsh school children's accounts of preference for and control over food choice. Health Promotion International, 23(2), 144-151.

[11] Eufic Review (2005). The determinants of food choice.Retrieved from www.eufic.org.

[12] Airle, C. (2011). Global advertising spending rose in 2010, Nielsen says. Retrieved from http://www.bloomberg.com/news/2011-0403/global-ad-spending-in-2010-rose-11-on-soccer-s-world-cup-neilsen-says.html

[13] Endicott, R.G. (2006). Top 100's measured media outlay hits \$98 billion globally. Retrieved from http://adage.com/images/random/globalmarketing2006.pdf

[14] Johnson, B. (2010). 100 Global Marketers.Retrieved from http://adage.coverleaf.com/advertisingage/20101206?pg=10\#pg10. 
[15] Consumer International (2008). Cereal offences: a wake-up call on the marketing of unhealthy food to children. Retrieved from http://www.consumersinternational.org/media/328567/cerealoffences13jan09-web1.pdf.

[16] Roberts, M., \& Pettigrew, S. (2007). A thematic content analysis of children's food advertising. International Journal of Advertising, 26(3), $357-367$.

[17] Karupaiah, T., Chinna, K., Loi, H. M., Lim, S. M., \& Noor, M. I. (2008). What's on Malaysian television? A survey on food advertising targeting children.Asia Pacific Journal of Clinical Nutrition, 17(3), 483-491.

[18] Australian Psychological Society (2009). Protecting children from junk food advertising. Retrieved from http://www.psychology.org.au/inpsych/junkfood/

[19] Bijmolt. T.H.A, Claassen, W., \&Brus, B. (1998).Children's understanding of TV advertising: effects of age, gender and parental control. Journal of Consumer Policy, 21(2), 171-194.

[20] Chaudhari, C., \&Marathe, M. (2007). Marketing to children: Issues \& remedies. Paper presented at the International Marketing Conference on Marketing \& Society, 8-10 April, 2007, IIMK.

[21] McDermott, L., Hastings, G., Stead, M., Carrigan, M., \& Harris, F. (2008). A review of the effects and interpretations of commercial messages and activities by children.Final Report of the Institute for Social Marketing, University of Stirling.Retrieved from http://www.education.gov.uk/publications/eOrderingDownload/Appendix-J Commercial-Messages-research.pdf.

[22] American Psychological Association (2004).Report of the APA Task Force on advertising and children. Retrieved from http://apa.org/pi/cyfladvertisingandchildren.pdf

[23] Jennings, N. A., \&Wartella, E. A. (2007). Advertising and Consumer Development. Mahwah, NJ: Lawrence Erlbaum.

[24] Boush, D. M., Friestad, M., \& Rose, G. M. (1994). Adolescent skepticism toward TV advertising and knowledge of advertiser tactics.Journal of Consumer Research, 21(1), 165-176.

[25] Mangleburg, T.F. \& Bristol, T. (1998). Socialization and adolescents' scepticism toward advertising.Journal of Advertising, 27 (3), $11-21$.

[26] Livingstone, S., \&Helsper, E. (2006). Does advertising literacy mediate the effects of advertising on children? A critical ex amination of two linked research literatures in relation to obesity and food choice.Journal of Communication, 56(3), 560-584.

[27] Butter, E. J., Popovich, P. M., Stackhouse, R. H., \& Garner, R. K. (1981). Discrimination of television programs and commercials by preschool children.Journal of Advertising Research, 21(2), 53-56.

[28] Macklin, C. M. (1987). Preschoolers' understanding of the informational function of television advertising. Journal of Consumer Research, 14(2), 229-239.

[29] Goran, M. I., Carpenter, W. H., McGloin, A., Johnson, R., Hardin, J. M., \&Weinsier, R. L. (1995). Energy expenditure in children of lean and obese parents.American Journal of Physiology, 268, 917-924.

[30] Stunkard, A. J., Berkowitz, R. I., Stallings, V. A., \&Schoeller, D. A. (1999). Energy intake, not energy output, is a determinant of body size in infants. American Journal of Clinical Nutrition, 69(3), 524-530.

[31] Treuth, M. S., Butte, N. F., \& Wong, W. W. (2000). Effects of familial predisposition to obesity on energy expenditure in multiethnicprepubertal girls.American Journal of Clinical Nutrition, 71(4), 893-900.

[32] Eck, L. H., Klesges, R. C., Hanson, C. L., \&Slawson, D. (1992). Children at familial risk for obesity: An examination of dietary intake, physical activity and weight status. International Journal of Obesity Related Metabolic Disorder, 16(2), 71-78.

[33] Fisher, J. O., \& Birch, L. L. (1995). Fat preferences and fat consumption of 3- to 5-year-old children are related to parental adiposity. Journal of American Dietary Association, 95(7), 759-764.

[34] Nguyen, V. T., Larson, D. E., Johnson, R. K., \&Goran, M. I. (1996). Fat intake and adiposity in children of lean and obese parents. American Journal of Clinical Nutrition, 63(4), 507-513.

[35] Hoyle, B. (2010). Medscape Medical News from the Pediatric Academic Societies (PAS) 2010 Annual Meeting.Retrieved from http://www.medscape.com/viewarticle/721613.

[36] AnuarZaini, M. Z., Lim, C. T., Low, W. Y., \&Harun, F. (2005). Factors affecting nutritional status of Malaysian primary school children.Asia Pacific Journal of Public Health, 17(2), 71-80.

[37] Dickinson, R. (2000). "Food and eating on television: impacts and influences". Nutrition \& Food Science, Vol. 30 Iss: 1, p. 24-29.

[38] Halford, J. C., Gillespie, J., Brown, V., Pontin, E. E., \&Dovey, T. M. (2004). Effect of television advertisements for foods on food consumption in children.Apepetite, 42, 221-225.

[39] Chernin, A. (2008). The effects of food marketing on children's preferences: Testing the moderating roles of age and gender. The Annals of the American Academy of Political and Social Science, 615(1), 101-118.

[40] Davies, M. M. (2010). Children, Media and Culture. Berkshire and New York: McGraw Hill and Open University Press.

[41] Institute of Medicine of the National Academies (2005). Preventing Childhood Obesity: Health in the Balance. Washington, D.C.: The National Academies Press.

[42] Obesity Policy Coalition (2008). A report submitted to the House of Representatives Standing Committee on Health and Aging: An inquiry into obesity. Retrieved from http://www.aph.gov.au/house/committee/haa/obesity/subs/sub094.pdf.

[43] Hastings, G., McDermott, L., Angus, K., Stead, M., \& Thomson, S. (2006). The extent, nature and effects of food promotion to children: A review of the evidence. Geneva, World Health Organisation, 2006. Retrieved from http://www. who.int/dietphysicalactivity/marketing/en/index.html

[44] McGinnis, J.M., Gootman, J.A., \&Kraak, V.I. (Eds.). (2006). Food marketing to children and youth: Threat or opportunity? Institute of Medicine of the National Academies.

[45] Gunter, B., \&Furnham, A. (1998). Children as Consumers: A Psychological Analysis of the Young People's Market. London: Routledge.

[46] Cole, T. J., Freeman, J. V., \&Preece, M. A. (1990). Body Mass Index Reference Curves for the UK, 1990.Archives of Disease in Childhood, $73,23-29$.

[47] Kirsh, S. J. (2010). Media and Youth: A Developmental Perspective. West Sussex: Wiley-Blackwell.

[48] Valkenburg, P. M., \&Buijzen, M. (2005). Identifying determinants of young children's brand awareness: Television, parents, and peers. Journal of Applied Developmental Psychology, 26(4), 61-72.

[49] Ansari, D., \&Dhital, B. (2006). Age-related changes in the activation of the intraparietal sulcus during nonsymbolic magnitude processing: An event-related functional magnetic resonance imaging study. Journal of Cognitive Neuroscience, 18(11), $1820-1828$.

[50] Schlaggar, B. L., Brown, T. T., Lugar, H. M., Visscher, K. M., Miezin, F. M., \& Peterson, S. E. (2002). Functional neuroanatomical differences between adults and school-age children in the processing of single words.Science, 296, 1476-1479.

[51] Livingstone, S. (2006) New research on advertising foods to children: An updated review of the literature Prepared for the Research Department of the Office of Communications (Ofcom), January. Published as Annex 9 to the report, Television Advertising of Food and Drink Products to Children. London: Ofcom, March 2006. 